\title{
Conditioned defensive burying in rats: Availability of burying materials
}

\author{
JOHN P. J. PINEL and DALLAS TREIT \\ University of British Columbia, Vancouver, British Columbia V6T IW5, Canada
}

\begin{abstract}
Rats shocked once by a stationary, wire-wrapped prod mounted on the wall of the test chamber incorporated sand, wooden blocks, or commercial bedding material on the floor of the chamber into a defensive response. They moved the available material toward and over the shock prod in all three conditions, adapting the response topography to the particular demands of the available material. In the sand and bedding conditions, the rats buried the prod by pushing and spraying piles of the material with snout and forepaws, whereas, in the blocks condition they picked up the blocks with their teeth and placed them individually around the prod. In Experiment 2, the rats buried the shock prod with blocks even when they had to first carry the blocks to the prod from the back of the chamber. Thus, conditioned defensive burying is not a simple, reflexive response to objects paired with a painful stimulus: it is a complex behavioral sequence that can vary as a function of the availability of burying materials.
\end{abstract}

We (Pinel \& Treit, 1978) have recently described a series of experiments in which domestic hooded rats shocked once through a stationary, wire-wrapped prod mounted on the wall of the test chamber returned to the prod and buried it with commercial bedding material from the floor of the chamber. Almost all of the rats shocked in this fashion sprayed at least some bedding material over the prod when the shocktest intervals were short, and significant amounts of burying were observed after the single conditioning trial even when the interval was as long as 20 days. Furthermore, those rats shocked by a prod in their home cages directed bedding material at the shock prod when they subsequently encountered it on the wall of the test chamber, whereas those receiving diffuse shock through a grid floor did not. In another experiment, every subject shocked by one of two identical prods mounted on opposite walls of the test chamber selectively buried the shock prod, thus providing convincing evidence that the burying behavior was being guided primarily by the previous association of shock and prod. Systematic decreases in the amount of burying were observed when specific aspects of the prod, such as its brightness or position, were changed in the interval between the contitioning trial and the test (Pinel, Treit, \& Wilkie, Note 1).

The conditioned burying phenomenon is interesting for at least three reasons. First, it provides evidence that aversive conditioning can be extraordinarily rapid, reliable, and enduring when cue (prod) and

This research was supported by a National Research Council of Canada grant awarded to the first author. Requests for reprints should be sent to John Pinel, Department of Psychology, University of British Columbia, Vancouver, British Columbia V6T 1W5, Canada. consequence (shock) are spatially, as well as temporally, contiguous, i.e., when localized shock is administered from a well-defined source. Second, it illustrates the weakness of the view (cf. Bolles, 1970) that the rat's defensive repertoire is limited to freezing, fleeing, and fighting. This view seems to have been shaped more by the constraining effects of traditional avoidance paradigms than by serious limitations in the rat's defensive capacity (Pinel \& Treit, 1978). Third, it shows that animals can avoid aversive objects by approaching and coping with them, a possibility not predicted by theories that have been devised to explain animal behavior observed in traditional avoidance chambers. The rats returned to the shock prod and buried it despite the fact that approaching the prod had just been followed by painful footshock.

The burying behavior of the rats in our previous studies was remarkably stereotyped. Each burying sequence typically began with the rat facing the shock prod from a distant part of the apparatus. Then the rat moved directly toward the prod pushing and spraying a pile of of bedding material ahead with rapid shoveling movements of its snout and alternating pushing movements of its forepaws. Although the consistency of this burying pattern facilitated its initial investigation, it also raised some serious questions concerning the adaptiveness of defensive burying in the rat's natural habitat. Such a stereotypical response pattern would be of marginal utility in habitats where available burying materials require more varied responses for their disposition. However, the stereotypical nature of the burying sequence in our previous investigations may simply have reflected the homogeneity of the commercial bedding which served as the only available burying material in our previous studies. 
Accordingly, the purpose of the present experiments was to demonstrate that rats could adapt their defensive burying pattern to changes in the kind (Experiment 1) or disposition (Experiment 2) of available burying materials.

\section{EXPERIMENT 1}

In Experiment 1, each subject was shocked by one of two prods mounted on opposite walls of the test chamber in the presence of one of three materials: (1) commercial bedding, (2) sand, or (3) wooden blocks. The wooden blocks were large enough so that they would be extremely difficult for a rat to pile over the prod using the snout and forepaw pushing motions characteristic of burying in our previous investigations.

\section{Method}

The methods were similar to those employed in our previous studies of conditioned defensive burying in rats (cf. Pinel \& Treit, 1978). The subjects were 30 naive male adult hooded rats (Canadian Breeding Farm and Laboratories, La Prairie, Quebec), individually housed in wire-mesh cages under controlled illumination (12-h light/dark cycle). Purina laboratory pellets and water were available continuously in the home cage.

Each of the 30 rats was randomly assigned to one of three conditions $(n=10)$. Every subject was treated in the same manner throughout the experiment, except that the type of material available in the $44 \times 30 \times 44 \mathrm{~cm}$ Plexiglas test chamber differed for the subjects in each condition. During all phases of the experiment, the chamber floor was covered with (1) $5 \mathrm{~cm}$ of San-i-cel, a commercial bedding material made of ground corn cob (Paxton Processing Co., Paxton, Ill.), (2) $5 \mathrm{~cm}$ of sand, or (3) $1001.0 \times 1.6$ $\times 2.4 \mathrm{~cm}$ wooden blocks placed so that the height of each was $1 \mathrm{~cm}$. The rats in each condition were handled and preexposed in squads of four or five to the test chamber in the presence of the designated burying material for 30 -min periods on each of 4 consecutive days. On Day 5 , the subjects were placed individually in the center of the test chamber between two identical prods that had been mounted in the middle of the two end walls $7.0 \mathrm{~cm}$ above the Plexiglas floor ( $2 \mathrm{~cm}$ from the sand or bedding material and $6 \mathrm{~cm}$ from the blocks). Each animal was allowed to explore the chamber and to contact each prod at least once without consequence. When the rat next touched one (randomly predetermined) of the two prods, a brief shock, initiated by the experimenter and terminated by the withdrawal of the subject, was delivered between two uninsulated wires wrapped around the prod. The shock circuit, composed of an $800-\mathrm{V}$ current source and an $80,000-\Omega$ resistor, delivers shocks averaging $7.9 \mathrm{~mA}(\mathrm{SD}=1.47)$ in intensity and $42.9 \mathrm{msec}(\mathrm{SD}=9.8)$ in duration when used in this manner (Pinel \& Treit, 1978). Following the shock, the behavior of each subject was viewed for $15 \mathrm{~min}$ over closed-circuit television, and the duration of burying, i.e., the amount of time spent moving material toward or over the prods, was recorded on an event recorder. Following each test, the heights of the material accumulated at the shock and control prods were recorded.

\section{Results}

Figure 1 shows that the subjects spent a substantial portion of their time burying, regardless of which material was available. Only one of the 30 subjects, an animal in the blocks condition, did not engage in at least some burying. It is also apparent in Figure 1 that the burying behavior was well directed. All 29 of

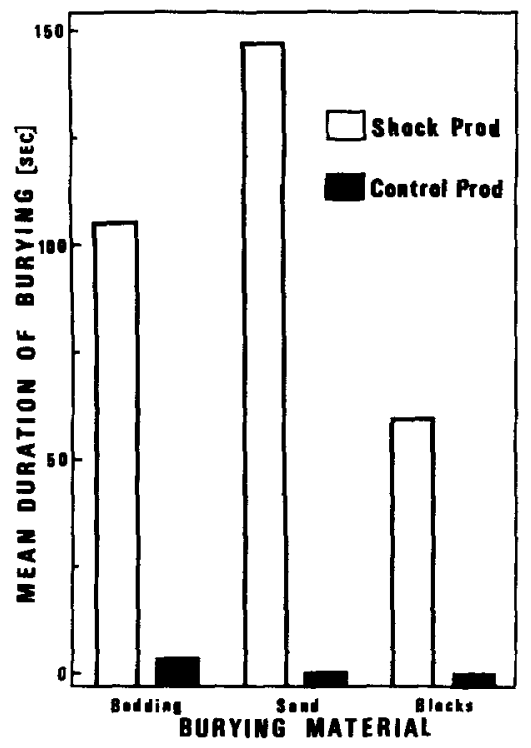

Figure 1. Mean duration of burying the shock and control prod with different burying materials.

the subjects that engaged in burying spent some time burying the prod which for them had been the source of the shock, whereas only 3 , all in the bedding condition, spent any time burying the control prod. Even in these three cases, the subjects spent most of their time burying the shock prod; they did not move material toward the control prod until the shock prod had been completely covered. A priori comparisons ( $t$ tests for dependent measures) between the total burying times accumulated by each subject at the respective prods confirmed that the subjects in all three conditions spent significantly more time burying the prod that had been associated with shock (bedding condition, $\mathrm{t}=7.83, \mathrm{p}<.00002$; sand condition, $\mathrm{t}=6.19, \mathrm{p}<.0001 ;$ blocks condition, $\mathrm{t}=2.75$, $\mathrm{p}<.02$ ). Burying behavior in the present context was always directed at one of the two prods.

The mean height of the materials accumulated at each of the two prods is presented in Figure 2. Analysis of these means provided an independent confirmation of the behavioral results. In each of the three experimental conditions, the average height of the burying material at the shock prod was significantly greater than that at the control prod (bedding condition, $\mathrm{t}=7.15, \mathrm{p}<.00005$; sand condition, $\mathrm{t}=6.16$, $\mathrm{p}<.0001$; blocks condition, $\mathrm{t}=2.68, \mathrm{p}<.02$ ). In addition to the obvious relation between the means of the two measures (compare Figures 1 and 2), the height of the piles accumulated by each individual rat accurately reflected the amount of time the rat had spent pushing material at each prod. The correlations between the amount of time spent burying the shock prod and the height of the material accumulated at the shock prod were $.89, .81$, and .80 (all ps $<.005$ ) for the bedding, sand, and blocks conditions, respectively. 


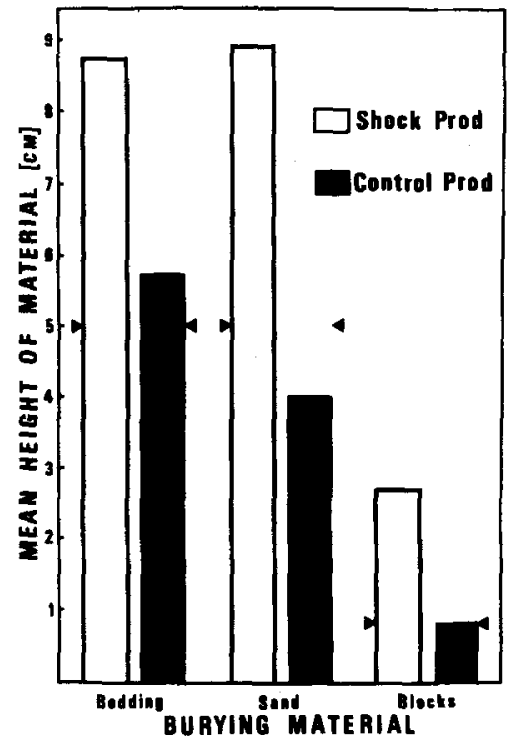

Figure 2. Height of burying materials at the shock and control prods after the 15-min test. Arrows indicate the height of the materials at the beginning of the test.

The pattern of burying behavior displayed by the animals in the bedding condition was indistinguishable from that displayed by those in the sand condition. In both conditions, the topography of the burying response was comparable to that described in previous experiments (Pinel \& Treit, 1978). The rats began each burying episode facing the prod from a distant part of the chamber. Then they moved directly toward the prod, pushing and spraying the material toward the prod with snout and forepaws. As in previous studies, these burying sequences were frequently interrupted by intervals of approach-avoidance behavior in which the rat would stretch forward until fully extended with its nose nearly touching the prod and then abruptly withdraw to the rear of the chamber.

Similar behaviors were also observed in those animals burying with blocks. They would move toward the prod pushing blocks ahead of them with snout and forepaws. Although this behavior was effective in accumulating blocks near the prod, it was necessary for the subjects to pick the blocks up in order to form a pile. Seven of the nine subjects that spent some time moving blocks toward the shock prod picked blocks up in their teeth and placed them in a pile with teeth and forepaws. None of these seven managed to completely cover the prod, $6 \mathrm{~cm}$ above the original level of the blocks, before the end of the test period, whereas in the other two conditions, where the prod was close to the initial level of the burying material, most of the subjects actually covered the prod. The rats' behavior indicated that the construction of the piles of blocks was not haphazard; on several occasions, a block just placed on top of a pile toppled to the bottom, from where it was quickly retrieved and returned to its original position atop the pile.

\section{Discussion}

The results of Experiment 1 confirm those of our previous studies of defensive burying in rats. Every rat shocked by one of two prods mounted on opposite walls of the chamber lined with commercial bedding material returned to the shock prod and buried it, and the few that pushed bedding at the control prod did not do so until the shock prod had been completely covered (Pinel \& Treit, 1978). Of greater interest here, however, is the finding that defensive burying is not limited to situations in which there is an available supply of commercial bedding material; all of the rats in the sand condition attempted to bury the shock prod, as did all but one of the subjects in the blocks condition. This finding is consistent with several incidental observations that have been made in our laboratory. In one case, a rat shocked in its home cage dismantled its nest of shredded paper and used it as burying material, and in another case several rats shocked by a prod on the Plexiglas floor of a barren test chamber placed their own feces on top of it.

The results of Experiment 1 also show that conditioned defensive burying is not a simple, reflexive response to objects paired with painful stimuli; rather, it is a complex behavioral sequence which varies as a function of the available burying material. In the blocks condition, the pushing and forelimb spraying movements, which rapidly produced large piles at the shock prod in the bedding and sand conditions, were not sufficient to gain the same end. Such movements were sometimes used to accumulate blocks in the vicinity of the prod, but to construct piles at the prod position the rats picked the blocks up in their teeth and deposited them around the prod.

These results, considered together, strengthen the suggestion that conditioned burying could be of considerable adaptive value in natural settings. Rats are capable of using a variety of materials to bury objects associated with aversive stimuli, even when the use of these materials necessitates changes in the topography of the burying sequence.

\section{EXPERIMENT 2}

The purpose of Experiment 2 was to demonstrate that rats will attempt to bury a source of aversive stimulation even when all of the burying material has to be transported by the rat to the site.

\section{Method}

The subjects were 20 naive male adult hooded rats purchased, housed, and fed in accordance with the methods of Experiment 1. As in Experiment 1, the subjects were habituated to the Plexiglas test chamber in groups of 4 or 5 for 30 -min periods on 4 consec- 
utive days. During the habituation periods, $1001.0 \times 1.6 \times$ $2.4 \mathrm{~cm}$ wooden blocks were distributed on the floor of the chamber. Each block was positioned during all phases of the experiment so that its height was $1 \mathrm{~cm}$. On Day 5 , the subjects were randomly divided into two groups of 10 , and shocked, as in Experiment 1, by one of the two prods (randomly predetermined). For the subjects in one of the groups, the 100 blocks were distributed on the half of the chamber containing the shock prod; for the subjects in the other group, the blocks were initially restricted to the distal half of the box. The behavior of each subject and the resulting redistribution of blocks was measured as in Experiment 1.

\section{Results}

Defensive burying was again a reliable consequence of the single conditioning trial. With the exception of two subjects in the condition in which the blocks were adjacent to the shock prod, all of the subjects engaged in at least some burying. Moreover, all 18 of the subjects which displayed the burying behavior directed it primarily at the shock prod; only 2 of these 18 moved any blocks at all toward the control prod. Thus, the subjects spent significantly more time burying the shock prod than they did the control prod in both conditions, when the blocks were adjacent to the shock prod $(M=36$ and $0 \mathrm{sec}$, respectively; $\mathrm{t}=2.35, \mathrm{p}<.04)$ and when the blocks were restricted to the far end of the chamber $(M=108$ and $.7 \mathrm{sec}$, respectively; $\mathrm{t}=2.45, \mathrm{p}<.04$ ).

These behavioral differences were confirmed by statistical analysis of the height of the pile accumulated at each of the two prods. Since, for each subject, the initial height of the blocks at the two prods was not equal at the start of the test, the increase in the height of the blocks at each prod, rather than the absolute height, was used as the index of burying. In both conditions, the average increase in the height of the blocks at the shock prod was about $3.7 \mathrm{~cm}$, but in neither condition was there a single instance in which the height of the pile at the control prod was increased (with blocks adjacent to the shock prod, $t=3.36$, $\mathrm{p}<.008$; with blocks restricted to the far end of the chamber, $\mathrm{t}=2.93, \mathrm{p}<.02$ ). As in Experiment 1 , no subject managed to completely cover the prod with blocks in the 15-min test period.

Between-group analyses did not reveal any significant differences between the two groups on either dependent measure. The group tested with the blocks and the shock prod at opposite ends of the box spent more time burying the shock prod $(M=107.6 \mathrm{sec})$ than did the subjects in which the shock prod and the blocks were in the same half of the chamber $(M=$ $36.1 \mathrm{sec}$ ); however, since the actual amount of time each rat spent moving blocks toward the shock prod varied considerably from subject to subject, this large difference in means was not statistically significant $(t=1.54, p>.10)$. Similarly, the groups did not differ significantly in terms of the amount of time spent burying the control prod $(t=1.48, p>$
.10) or in terms of the increase in the height of the blocks at either the shock $(t=.024, p>.10)$ or control $(\mathrm{t}=0, \mathrm{p}>.10)$ prods.

\section{Discussion}

In all previous studies of defensive burying, burying material was always available in the area immediately adjacent to the source of the shock. In Experiment 2, rats buried the shock prod even when the burying material was initially restricted to the other end of the chamber. After being shocked, the rats carried or pushed the blocks toward the shock prod for use in its subsequent burial. This observation supports the view (Hudson, 1950; Pinel \& Treit, 1978) that burying can function as an effective defensive response in the rat's natural environment, an environment where burying materials are not always readily available. It also is consistent with Hudson's (1950) speculation that a rat in one of his avoidance experiments was attempting to wrench a wire from the side of the cage so that it could be used to bury a shock source.

\section{GENERAL DISCUSSION}

In view of the general interest of experimental psychologists in learning phenomena, it is surprising that conditioned defensive burying has not long been the focus of systematic experimental investigation. Over 25 years ago, Hudson provided extensive, but unquantified, descriptions of conditioned defensive burying in rats, but until recently (Pinel \& Treit, 1978) burying behavior has not been used as an index of aversive conditioning. There have, however, been a number of isolated observations of defensive burying by rodents in natural habitats. They have been observed to bury novel objects such as traps (cf. Hudson, 1950), to spray sand and dirt at predators (Owings \& Coss, 1978), and to seal burrow entrances to repel intruders (Calhoun, 1962). However, because these observations were uncontrolled, it is not possible to argue convincingly that the burying in each case was conditioned. In fact, it is clear that, in at least some instances, burying is unconditioned. Owings and Coss (1978) recently reported that laboratoryreared ground squirrels sprayed sand over snakes, but not over a comparable mechanical control object, the first time they were encountered. Moreover, Pinel and Treit (1978) found that a small number of unshocked rats would bury a shock prod when it was first introduced into the test chamber.

One of the likely reasons why conditioned defensive burying has not attracted more comment in the "learning" literature is that it cannot be readily incorporated into existing views of aversive conditioning. Even Bolles' theory of avoidance learning, which has provided a major stimulus for our studies of conditioned defensive behavior, cannot account com- 
pletely for this phenomenon. Bolles (1970) argued that only the rats' innate species-specific defensive reactions, i.e., fleeing, freezing, and aggressive behavior, can be readily learned by the rat in aversive situations. His main conclusion was that, in aversive situations, the rat's behavior is limited to fleeing, freezing, and aggressive behavior, and that avoidance learning progresses when the ineffective responses are eliminated by punishment. For example, in standard shuttlebox conditioning experiments, freezing and aggressive responses are consistently punished, leaving flight as the dominant response. On the basis of our studies of conditioned defensive burying, it seems clear that Bolles' list of species-specific defensive behaviors must be extended to include defensive burying. Even with this addition, it is difficult to understand how burying could be left as the dominant avoidance response after only a single conditioning trial. Freezing, fleeing, and aggressive behavior have been rare in our studies of conditioned defensive burying, and in the few instances in which they have occurred during the test they have not been punished by an additional shock. In fact, rats approached the source of aversive stimulation while burying it, even though their initial approach to the source had been followed by footshock.

Despite the ob ious difficulty involved in integrating conditioned defensive burying into existing views of aversive conditioning, the growing concern for the ethological significance of laboratory learning phenomena should spark considerable interest in the conditioned burying phenomenon. In fact, the present experiments illustrate several features of conditioned defensive burying which are likely to make it a useful addition to the paradigms available for studying defensive behavior and for drawing inferences about the learning processes that control it. First, conditioned defensive burying is an extremely reliable phenomenon; 29 of the 30 animals in Experiment 1 and 18 of the 20 in Experiment 2 engaged in at least some burying behavior. Second, the present experiments illustrate the generality of the response. The rats in all conditions buried, despite attempts to disrupt burying, by using awkward burying material (Experi- ment 1) or by limiting its initial distribution to the far end of the chamber (Experiment 2). Third, there are two different indices of burying, time spent burying and the height of accumulated material, that are highly correlated but require neither specialized equipment nor training for their quantification. Fourth, the burying response is selectively directed at those particular stimuli previously associated with the aversive stimulus, thus making it possible to use subjects as their own controls. In both experiments, every subject that spent some time burying spent the majority of that time burying the shock prod despite the presence of an identical control prod on the opposite wall. Although this point has been made previously, Experiment 2 is a particularly compelling demonstration of the selectivity of defensive burying. When all of the blocks were located next to the control prod, the rats carried or pushed these blocks away from the control prod to the other end of the chamber so that they could be used to bury an identical prod that had been the source of footshock.

\section{REFERENCE NOTE}

1. Pinel, J. P. J., Treit, D., \& Wilkie, D. M. Constraints on avoidance learning: Burying an unfounded assumption. Invited paper presented at the Northeastern Regional Meeting of the Animal Behavior Society, St. John's, Newfoundland, October 1977.

\section{REFERENCES}

Bolles, R. C. Species-specific defense reactions and avoidance learning. Psychological Review, 1970, 71, 32-48.

CALhoun, J. B. The ecology and sociology of the Norway rat. Bethesda, Md: U.S. Department of Health, Education and Welfare, 1962.

Hudson, B. B. One-trial learning in the domestic rat. Genetic Psychology Monographs, 1950, 41, 99-145.

Owings, D. H., \& Coss, R. G. Snake mobbing by California ground squirrels. Adaptive variation and ontogeny. Behaviour, $1978,62,50-69$.

Pinel, J. P. J., \& Treit, D. Burying as a defensive response in rats. Journal of Comparative and Physiological Psychology, $1978,92,708-712$.

(Received for publication July 11, 1978; revision accepted November 20,1978 .) 